\title{
O CORPO É MEU OU TEU?
}

\author{
Andressa Leoni Leandro da Silva Borges ${ }^{1}$ \\ Rarielle Rodrigues Lima²
}

\section{RESUMO}

O texto aqui pretende trazer à reflexão acerca do "corpo feminino" e sua relação com a Moral Cristã, partindo do ponto de vista da dominação patriarcal ao longo do século na história da sociedade e o interculturalismo mediado através da educação do que "é o corpo feminino para a Igreja" e como essa questão da dominação religiosa sobre o corpo influencia atualmente a mulher no aspecto sócio político no Brasil.

Palavras-chave: Corpo; feminismo; religião; Igreja; Brasil.

\begin{abstract}
The text here intends to bring to reflection about the "female body" and its relationship with the Christian morals, starting from the point of view of patriarchal domination throughout the century in the history of society and the inter-culturalism mediated through education than "It is the female body for the Church" and how this issue of religious domination over the body currently influences women in the socio-political aspect in Brazil.
\end{abstract}

Keywords: Body; feminist; religion; Church; Brazil.

\section{RESUMEN}

El texto aquí tiene como objetivo llevar a la reflexión sobre el "cuerpo femenino" y su relación con la moral cristiana, partiendo del punto de vista de la dominación patriarcal a lo largo del siglo en la historia de la sociedad y la interculturalidad mediada a través de la educación de lo que "es el cuerpo femenino para la Iglesia" y cómo este tema de la dominación religiosa sobre el cuerpo influye actualmente en las mujeres en el aspecto sociopolítico en Brasil.

Palabras clave: Cuerpo; feminismo; religión; Iglesia; Brasil.

1 Doutoranda em Ciências da Educação, pela Universidade Lusófona de Humanidades e Tecnologias - ULHT, Faculdade de Ciências Sociais, Educação e Administração Membro do Centro de Estudos Interdisciplinares em Educação e Desenvolvimento - CeiED Lisboa, Portugal e-mail: andressa_leoni@hotmail.com

2 Doutora em Ciências Sociais, pela Universidade Federal do Maranhão - Membro do Grupo de Estudo em Gênero, Memória e Identidade (GENI/UFMA) e membro do Grupo de Estudos e Pesquisas Pedagógicas em Educação Física (GEPPEF/UFMA) - São Luís, Brasil e-mail: rariellerodrigues@gmail.com 


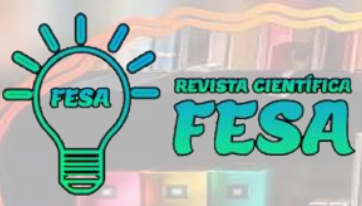

\section{INTRODUÇÃO}

Durante séculos, as várias sociedades foram regidas por fortes interferências religiosas, uma delas foi a educação doméstica feminina que funcionava como limitações e regras dos dogmas das Igrejas Cristãs, ou seja, a Igreja Católica possuía uma aliança com a Família e a Medicina, por essa razão, ela, tinha forte domínio no papel social da mulher que se prolongou até os dias de hoje. (Fonseca, 2011, p. 216). De acordo com Margareth Rago, até o fim dos anos de 1960 a identidade da mulher esteve ligada ao lar nos papéis de dona de casa e mãe: "[...] Segundo esta, as mulheres deveriam desejar ser mãe, acima de tudo, como se sua suposta essência se localizasse um órgão específico - o útero, capaz de responder por todos os bons e maus funcionamentos fisiológicos, psíquicos e emocionais." (Rago, 2004, p.31-32).

Moldada no âmbito da moral sexual, a partir dos preceitos da lgreja Católica, a mulher foi e ainda é, de certa forma, privada dos seus sentimentos, ações e atitudes. Aliás, a referida aliança institucional, criou vários estereótipos à muIher, dentre os quais se destacam o de pecadora, incapaz, histérica, entre outros. Lembramos que de acordo com Jurandir Costa (1999), no Brasil, em meados do século XIX havia um discurso na sociedade sobre medicina higienista, onde apregoava que a vocação natural das mulheres, de acordo com suas disposições físico-corporais, seria exclusivamente a maternidade. Ou seja, por décadas, o discurso do prazer da mulher estava estritamente relacionado com a satisfação espiritual, doméstica e materna. Segundo o mesmo autor, no aspecto dessa construção sobre a natureza da mulher, consolidou uma distinção entre a "natureza feminina" e a "natureza masculina", como polos opostos, reforçando ainda mais a conotação religiosa do papel da mulher na sociedade.

Para aquele que é religioso ou compartilha um sentimento espiritual, o corpo sempre foi submetido aos desígnios divinos. Desígnios estes que sempre foram diferenciados para "homens" e "mulheres" e, no que diz respeito a certo tipo de "ditadura corporal", sempre focaram mais nas segundas do que nos primeiros. Carlos Bauer (2001) esclarece que já na época do feudalismo, e continuando até o século XIII, a mulher era acusada de heresia, pois essa era uma maneira de torná-la imperfeita e, assim, impedi-la de executar as mesmas funções do homem, uma vez que isso poderia ser perigoso. O autor nos mostra 


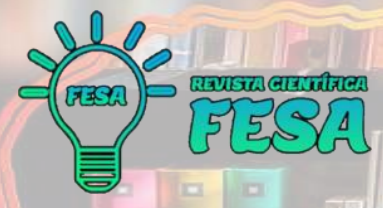

Set. 2021

v. 1, n. 8, 41-62

ISSN: $2676-0428$

alguns adjetivos atribuídos à personalidade feminina por um bispo germânico na Idade Média. Para ele, as mulheres eram pérfidas, luxuriosas, impulsionadas naturalmente para a fornicação e, devido à sua fragilidade ante os perigos da carne, exigia da moral cristã uma aguda desconfiança com relação ao prazer. (Bauer, 2001).

De acordo com Arilda Ribeiro (2000), no Brasil colônia, o homem era quem tomava as decisões, e dominava, por meio da família patriarcal, e que o significado de família, vem de famulus, uma expressão latina que quer dizer: escravo doméstico de um senhor. Emannuel Araújo (2010, p.46), afirma que a Igreja e a família exerciam forte pressão sobre o "adestramento" do sexo feminino, justificando através da Bíblia, que o homem era superior, e portanto cabia a ele exercer a sua autoridade, em Epístola aos Efésios: "As mulheres, como Cristo é a cabeça da Igreja. Como a Igreja está sujeita a Cristo, estejam as mulheres em tudo sujeitas aos seus maridos" (Shedd, 1998).

E foi a partir desse enquadramento da Moral Cristã, que a educação feminina católica no Brasil, tornou-se um ponto importante na sociedade, no que diz respeito a funcionalidade da mulher para a lgreja. E, pensando neste viés muitas instituições de cunho católico vindo da Europa, incrementou seus dogmas e preceitos para moldar cada vez mais as mulheres. A ideia principal, para estas instituições católicas era que através da educação religiosa fosse possível definir o papel do homem e da mulher na sociedade brasileira, e por isso a política para a atual colônia portuguesa, era conduzida para que o ensino de meninas e meninos fossem específicos para a necessidade de transformar um povo leal aos preceitos do Estado Português.

Lembramos que esse poder da Igreja dispunha no período colonial, só foi devido ao Catolicismo, também conhecido como Cristandade. Para Dermir Azevedo (2004, p. 111), "a Igreja era uma instituição subordinada ao Estado e a religião oficial funcionava como instrumento de dominação social, política e cultural." Durante as primeiras décadas do século XIX no Brasil, a Igreja Católica construiu um discurso que era sustentado pela dualidade entre o bem e o mal, contrapondo o mundo moderno representado por novas concepções de organização social, considerado contrário a Deus e nocivo a população e contrário aos valores morais, a família cristã e a autoridade.

Para Maria Bandeira (2000), a Igreja se colocava como guardiã dos valores 


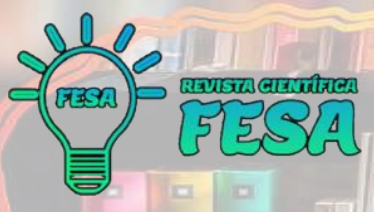

Set. 2021

v. 1, n. 8, 41-62

ISSN: 2676-0428

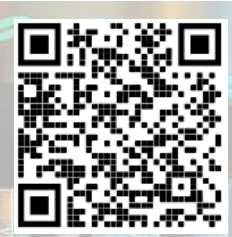

"vitais" e da ordem social, e também a única via de comunicação com Deus. Lembramos que a Marcha da Família com Deus pela Liberdade, evento este que impulsionou o golpe militar, era composta em sua maioria por mulheres casadas católicas, que percorreu as ruas de São Paulo em 19 de março de 1964, dias antes do golpe ocorrer. Reforçando que a maioria das mulheres se encontrava sob a influência de uma ideologia conservadora, apoiada as concepções da Igreja.

Advindo das grandes alterações políticas pós ditadura, sem dúvida as muIheres, foram o segmento que mais de modificou entre as décadas de 1960 e 1970. Tiveram que se adaptar com as novas mudanças na vida cotidiana, no mercado de trabalho e consequentemente na escolha de ser ou não mãe. Decisões antes, travadas de forma lenta e automática de acordo com os interesses masculinos e subordinadas pela Igreja, neste momento, com a velocidade das alterações socio políticas no Brasil, precisaram obter mais escolaridade e dinamizar suas relações tanto com os homens, como com outras mulheres.

Desse modo, as lutas de igualdade de direitos com relação ao gênero masculino, por exemplo, com o movimento feminista, a mulher conquistou seu espaço na sociedade, obtendo o direito de votar e de trabalhar fora do lar. (Alves; Pitanguy, 1991). Porém, ao fim da ditadura, e com o início da redemocratização no país e atrelado ao fortalecimento do capitalismo, a mulher passou a ter não apenas funções reprodutoras, mas assumiu, também, tarefas produtoras de força de trabalho como resultado do maior espaço conquistado na sociedade, para atender às novas complexidades sociais do processos de industrialização, urbanização e aumento demográfico progressivo, o poder disciplinar teve uma missão primordial criar mecanismos de controle, e o corpo, a sexualidade e aquilo que se entende como único do ser humano, ainda hoje é pauta de discussão, e considerado tabu. Já dizia Foucault, em sua obra Vigiar e Punir: "é dócil um corpo que pode ser submetido, que pode ser utilizado, que pode ser transformado e aperfeiçoado." (Foucault, 1987, p.163). Neste aspecto o autor ele emerge em dissertar que o corpo a partir do século XVIII, foi o principal objeto de investimentos nas diversas sociedades, e tal método era chamado por ele de 'disciplina', e que era possível encontrar tal método de controle, principalmente nos conventos, nos exércitos e nas oficinas de trabalho.

No entanto, a discussão do controle do corpo, não somente a lgreja e as 
parcelas conservadoras da sociedade brasileira negam-se a discuti-la, considerando-a algo promíscuo e atentatório à moral e aos bons costumes, mas até mesmo as organizações de esquerda e as próprias militantes repudiavam as tentativas da discussão neste sentido, optando pelo viés estritamente político. (Colling, 2015, p. 375).

\section{A TAL POLÍTICA DO CORPO, O QUE É ISSO AFINAL?}

O corpo, essa carcaça que protege nossos órgãos, que em conjunto com o todo nos torna único, mas que ao mesmo tempo trás estranheza, pudor, medo; ao se falar, olhar ou mesmo tocar. O que faz o corpo ser tão controversamente discutido em pautas de todas as áreas? Como entender que o maior signo da desigualdade da mulher, é simplesmente seu útero? Essa é de fato a maior e única diferença entre homens e mulheres: a capacidade de gerar um outro ser?

Historicamente o corpo feminino foi desqualificado, desde os mais diversos discursos médico-filosófico dos antigos gregos, perpassando pela narrativa judaico-cristã, nos tais discurso médico-psiquiátrico e até psicanalítico, sempre foi alvo de suspeitas e surpresas. (Colling; Acom, 2019, p. 131). De acordo com as autoras Silvana Goellner e Márcia Figueira:

\footnotetext{
"Um corpo não é apenas um corpo. É também o seu entorno. Mais do que um conjunto de músculos, ossos, vísceras, reflexos e sensações, o corpo é a roupa e os acessórios que o adornam, as intervenções que nele se operam, a imagem que dele se produz, as máquinas que nele se acoplam, os sentidos que nele se incorporam, os silêncios que por ele falam, os vestígios que nele se exibem, a educação de seus gestos... enfim, é um sem limite de possibilidades sempre reinventadas, sempre à descoberta e a serem descobertas. O corpo é o que dele se diz, isto é, o corpo é construído, também, pela linguagem." (Goellner; Figueira, 2002, p. 02).
}

Entendemos a partir da fala das autoras que, o corpo carrega uma culturalização, transpondo uma significância para a história de uma sociedade, assim como afirma Louro (2000, p.03) "Os corpos ganham sentido socialmente. A inscrição dos gêneros - feminino ou masculino - nos corpos é feita, sempre, no contexto de uma determinada cultura, e, portanto, com as marcas dessa 
cultura."3

Para Mauss (1950), o conjunto de hábitos, costumes, crenças e tradições que caracterizam uma cultura também se refere ao corpo. Assim, há uma construção cultural do corpo, com uma valorização de certos atributos e comportamentos em detrimento de outros, fazendo com que haja um corpo típico para cada sociedade. Esse corpo, que pode variar de acordo com o contexto histórico e cultural, é adquirido pelos membros da sociedade por meio da imitação prestigiosa: os indivíduos imitam atos, comportamentos e corpos que obtiveram êxito e que viram ser bem-sucedidos.

Ao longo do tempo, o corpo se tornou o vetor de discursificação ${ }^{4}$ destes valores. Uma breve digressão a respeito das alterações no exercício de poder sobre o corpo nos permite antever como ele se tornou o espaço de silenciamento das minorias. Antes, pela vigilância e adequação à produção; agora, pela exclusão simbólica daqueles que não servem aos propósitos de performance típicos de uma sociedade de consumo. (Lucas e Hoff, 2008, p. 139). Judith Buther, neste contexto vai dizer que "o sujeito é constituído através da força da exclusão e da abjeção, uma força que produz um exterior constitutivo relativamente ao sujeito, um exterior abjeto que está, afinal, dentro do sujeito, como seu próprio e fundante repúdio." (Butlher, 1999). No entanto, o componente corpo ao se moldar mediante a uma determinada sociedade, abre designo na relação de poder, seja por ora através da religião, traçando modelos e regras, ou através da aplicação da lei como estratégia de controle social do Estado, e neste aspecto, Foucault afirma que:

\begin{abstract}
Nas relações de poder, a sexualidade não é o elemento mais rígido, mas um dos dotados de maior instrumentalidade: utilizável no maior número de manobras, e podendo servir de ponto de apoio, de articulação às mais variadas estratégias. Não existe uma estratégia única, global, válida para toda a sociedade e uniformemente referente a todas as manifestações de sexo: a ideia, por exemplo, de muitas vezes se haver tentado, por diferentes meios, reduzir todo o sexo à sua função reprodutiva, à sua forma heterossexual e adulta e à sua legitimidade matrimonial não se explica, sem a menor dúvida, os múltiplos objetivos visados, os inúmeros meios postos em ação nas políticas sexuais
\end{abstract}

3 Aqui, a autora Guacira Lopes Louro, defende que não há nada de natural na concepção de corpo. Para ela, a identidade de gênero e consequentemente sexual, são definidas pelas relações sociais, moldadas precisamente pelas "redes de poder" de uma determinada sociedade.

4 Este termo se refere o modo que o tema "gênero" e suas vertentes, como por exemplo, neste artigo discutindo sobre o corpo, tem sido reproduzido nos demais conjuntos de saberes, e como estar sendo representado o papel da mulher de forma prática e teórica pela sociedade. 

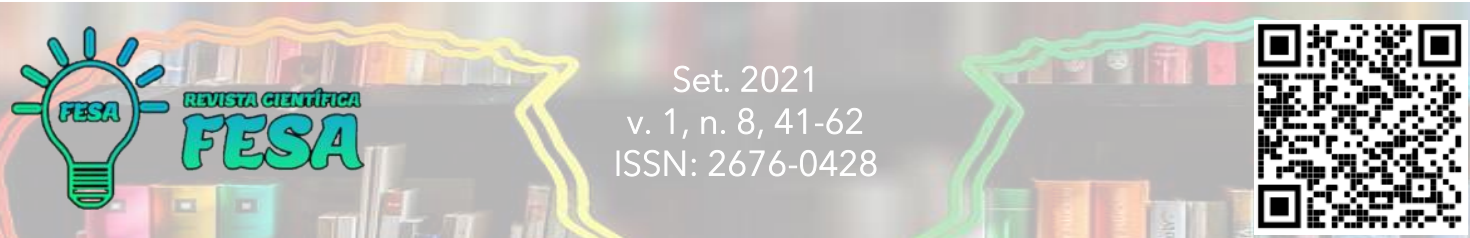

concernentes aos dois sexos, as diferentes idades e classes sociais. (Foucault, 1988, p. 98).

Ou seja, há intrinsecamente um poder exercido de forma ascendente, atrelado a pequenos grupos de indivíduos, quer exercem tal poder, quer são submetidos a ele. $O$ conceito foucaultiano sobre a relação de poder, se fortaleceu a partir da segunda metade do século XVIII, com crescimento do capitalismo. Foucault acreditava que a sociedade capitalista só foi possível mediante controle disciplinar através de novos adventos tecnológicos tornando os "corpos dóceis" sujeitos ao "soberano", aqui representado pelo Estado. O filósofo dizia que o sujeito, de acordo com o conceito de dispositivo, criado por ele, eram máquinas, estratégias e táticas que tinham função de serem corpos e almas, porém, também de fabricar populações para responderem as urgências históricas em determinada sociedade, como por exemplo: a escola, a família, o hospital e entre outros dispositivos. (Foucault, 1979).

No Brasil, a forte influência das escolas católicas, antes categorizadas pelo sexo, tornou a relação de poder mediada pela a Igreja, e moldou a política do corpo da mulher brasileira, enraizando muitos estigmas que carregamos até hoje. Nas escolas "os corpos são ensinados, disciplinados, medidos, avaliados, examinados, aprovados (ou não), categorizados, magoados, coagidos, consentidos..." (Corrigan, 1991, p. 210). Lembro-me de ouvir, quando estudei numa escola católica, na região do nordeste, muitas frases assim 'Meninas devem sentar de pernas cruzadas'; 'Uma mulher que saiba costurar casa mais rápido que as demais'. Talvez hoje, tais frases não chocam tanto, ou mesmo sejam levadas em consideração como algo notoriamente importante, porém a condição educativa de muitas mulheres brasileiras está entrelaçada a muitas dessas afirmações.

$\mathrm{E}$, devemos a isto, principalmente ao sistema patriarcal herdado como cultura social, no período colonial brasileiro, onde o homem era responsável e obtinha o direito de controlar a vida da mulher, tanto no modelo de pai, e posteriormente no modelo de marido. Este último, desempenhando o dever principal de sustentar à família, enquanto a mulher apresentava a funcionalidade essencial de reprodutora (consoante a isso também de levar prazer sexual ao seu senhor marido), cuidadora do lar, gerenciadora das tarefas dos escravos e por último e não menos importante educadora dos filhos. Ou seja, a mulher está(va) sempre submissa aos interesses patriarcais, "independentemente das diferenças entre 


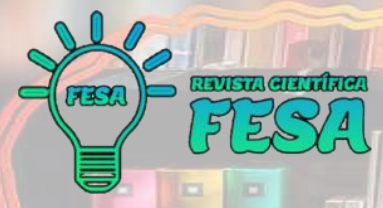

as camadas sociais, o processo de socialização impunha a disposição da mulher a obedecer, o conhecimento claro do que era certo e do que era errado, bem como a capacidade de se conter." (Fischer, 2001).

Reforçando também, que as mulheres muitas vezes ao adentrar o casamento não apresentavam afetividade para com o esposo, normalmente o casamento se tornava um simples contrato econômico acordado pelo pai ou em alguns casos pelo irmão primogênito. (ARAÚJO, 2010). Ainda nos dias de hoje, é comum associar um "bom casamento", quando a mulher casa com um homem de bens e posses. Acredita-se na cultura patriarcal, o homem que tem a obrigação de levantar o sustento para a futura família que está a iniciar, e a mulher como coadjuvante neste cenário, terá somente o prazer de usufruir do trabalho do esposo.

\section{O QUE É O CORPO FEMININO PARA A RELIGIÃO?}

Guacira Louro (2003), diz que "os significados dos corpos deslizam e escapam, eles são múltiplos e mutantes. Até mesmo o gênero e a sexualidade aparentemente deduzidos de uma "base" natural - são atributos que se inscrevem e se expressam nos corpos através das artimanhas e dos artifícios da cultura." Ou seja, na grande maioria as sociedades em algum momento o masculino e o feminino é distinguido ao corpo, reforçando de acordo com a autora acima, que os significados dos corpos são alterados ao longo da existência das sociedades e dos sujeitos, na medida que mudam os hábitos, a medicina, a tecnologia e as autoridades do estado.

Para Simone de Beauvoir, em seu trabalho "O segundo Sexo" (1970) ser mulher, significa ser Outro, enquanto que ser homem, indicava ser "Eu", ou seja, ser mulher é ser o oposto do homem, inferior, menor, em contrapartida ser homem seria não ser mulher, superior, maior. Beauvoir relata ainda quando o assunto é a educação das meninas, essas estão sempre direcionadas para tornarem mulheres, desde o uso de vestimentas relacionadas a vestidos e os brinquedos de cunho doméstico, a obediência sem elevar seus próprios desejos são sem dúvidas disposições para que se torne a mulher que está destinada a ser.

No entanto é fato que os homens e mulheres, pela categoria de gênero, são corpos que possuem diferenciações sexuais, e de acordo com Suely Kofes 


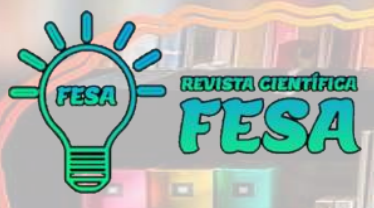

Set. 2021

v. 1, n. 8, 41-62

ISSN: $2676-0428$

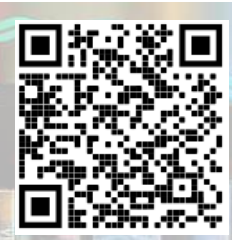

(2009), independente do órgão genital, os comportamentos podem ser masculinos ou femininos. Nas diversas sociedades os símbolos culturais tornam-se instrumento necessário na educação de um povo. (Porter, 1992, p. 325). E quando o assunto é corpo, este sempre esteve relacionado com os planos divinos, sejam estes pertencentes a diferentes aspectos, como por exemplo a cura de patologias mediante à vontade de Deus, saúde ou mesmo questões de género. A religião sempre educou "homens" e "mulheres" de formas distintas, e na maioria dos textos que abordam o assunto, apontam para certa inferioridade feminina.

Isto deve-se, em parte, à educação religiosa, que é, desde os primórdios (institucionalizada ou não), um dos símbolos mais fortes presentes na vida humana. A religião cristã aponta e fortalece não só a diferença entre o corpo e a alma, e a superioridade da última, como aponta também para as diferenças entre o homem e a mulher na criação de Deus. Mas, sabemos que não existe um corpo a-histórico e que este traz marcas do tempo que o modificam e o transformam a cada dia (Soares; Fraga, 2003).

Ressaltamos ainda que para cada época histórica existe um tipo específico de corpo idealizado, no entanto essas representações sociais que se fazem do corpo, nem sempre foram as mesmas para todas as épocas, espaços e culturas. Cada cultura tem sua maneira própria de pensar e vivenciar o corpo e atribuirIhe um lugar na esfera social. Isso denota que identidade corporal é inventada e construída em determinados contextos culturais e em certas circunstâncias. (Santos, 2011, p. 407)

David Le Breton (2009, p.70), já dizia: “o corpo metaforiza o social e o social metaforiza o corpo. No interior do corpo são as possibilidades sociais e culturais que se desenvolvem." Sem sombra de dúvida, rapazes e moças são biologicamente diferentes, mas a socialização exacerba essas diferenças e isso se torna uma bola de neve. Pierre Bourdieu 2003, p.20) acredita que essas diferenças são constituídas de fatores biológicos e sociais: "[...A diferença biológica entre os sexos, isto é, entre o corpo masculino e o corpo feminino, e especificamente, a diferença anatômica entre os órgãos sexuais, pode assim ser vista como justificativa natural da diferença socialmente construída entre os gêneros e, principalmente, da divisão social do trabalho...]".

Jurgen Habermas (2007, p.21), afirmou que "o organismo do recém-nascido só consegue formar-se como homem mediante a assunção de interações 


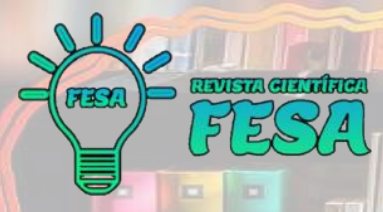

sociais", ou seja, mesmo que nosso corpo torne a primeira forma de identificação dos sujeitos, o homem como ser humano possui uma natureza social. O corpo integra representações coletivas que são determinadas através da cultura, em um determinado momento da vida, tornando o corpo uma história única, porém que se funde com a história social da humanidade.

Para a Igreja Católica, o ser humano alcança durante a primeira e segunda infância sua consciência de identidade e que consequentemente é uma consciência da diferença. Diferença essa que integra a identidade sexual, que é psicobiológica do próprio sexo e da distinção em relação ao outro sexo; e também a identidade de gênero (conhecida como gender), que é psicossocial e cultural do papel de cada um desempenha na sociedade. De acordo com o Conselho Pontifício para Família (CPF, 2000, n. 8), a identidade sexual e a de gênero se "complementam", em um processo de integração "correto e harmônico"; A integração da personalidade se realiza como reconhecimento da plenitude da "verdade interior da pessoa", unidade de alma e corpo.

Sobre mulher, a Igreja Católica ainda sublinha duas tendências, uma da subordinação onde diz que a mulher é "antagônica do homem", onde os abusos de poder se enfrentam com busca do poder levam à rivalidade entre os sexos. Ou seja, a identidade e o papel de cada um (homem e mulher) são assumidos em prejuízo do outro. A segunda tendência acaba por se tornar a consequência da primeira, ou seja, a diferença corpórea, chamada sexo, é minimizada; e a dimensão cultural, chamada gênero, é maximizada e considerada primária. Portanto, a antropologia que obscurece a dualidade dos sexos em favor de perspectivas igualitárias para a mulher, questiona a natureza biparental da família, composta de pai e de mãe, e equipara a homossexualidade à heterossexualidade, num novo modelo de "sexualidade polimórfica". (CDF, 2004, n. 4).

As duas questões que sempre foram uma grande "pedra no sapato" da Igreja: a sexualidade e a concepção de natureza humana, tornando cada vez mais discutidos em conferências eclesiásticas no mundo. Nota disso foi a frase do cardeal Angelo Bagnasco, Arcebispo de Gênova e presidente da Conferência Episcopal Italiana, que expressou sua total indignação quanto a 'ideologia de 


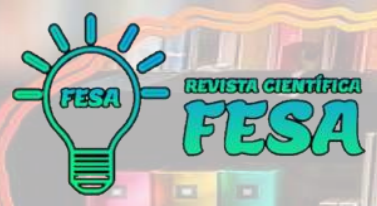

gênero'5, sobre iniciativa de se difundir na escola, três documentos destinados ao primário e ao secundário: "Educar para diversidade", como estratégia governamental italiana anti-homofobia:

\begin{abstract}
"É a leitura ideológica do 'gênero' uma verdadeira ditadura que quer anular a diversidade, homologar tudo até tratar a identidade do homem e da mulher como puras abstrações. É de perguntar-se com amargura se se quer fazer da escola 'campos de reeducação', de 'doutrinação'. Mas os pais ainda têm o direito de educar os próprios filhos, ou foram desautorizados de fazê-lo? Pediu-se a eles não apenas consentimento, mas antes a permissão explícita? Os filhos não são materiais de experimentação nas mãos de ninguém, nem mesmo de técnicos ou de ditos especialistas. [...]" (ADISTA ONLINE, 05 de abril 2014, s/p.).
\end{abstract}

Sabemos que a discussão da "ideologia de gênero", como é intitulado para a Igreja, sempre foi uma questão delicada, e sendo assim, é importante lembrar que essa expressão "ideologia de gênero" neste caso, foi utilizada pela primeira vez o fim da década de 90, com intuito de desqualificar a natureza feminina que eram contrárias a visão patriarcal cristã. No texto público escrito pelo Bispo "Joseph Ratzinger", através da Congregação para a Doutrina da Fé (CDF):

\begin{abstract}
"O lugar que, verdadeiramente, é devido às mulheres é privado - é da família, já que "é nesta que, em primeiro lugar, se plasma o rosto de um povo; [... que] os seus membros adquirem os ensinamentos fundamentais" (número 13). Cabe, pois, à mulher, nesta perspectiva, ser a principal reprodutora (no sentido físico e social) do sistema que a submete e da ideologia que a suporta, diríamos nós. Mais: cabe à mulher "deixar-se converter e reconhecer os singulares valores, fortemente eficazes, do amor pelo outro, de que a sua feminilidade é portadora" (número 17). (2004).
\end{abstract}

No entanto, a discussão em pauta só mantém viva, principalmente porque existem muitos estudiosos que defendem que "toda religião explica não só a origem da ordem do mundo natural, mas também do mundo humano" (Chauí, 1997, p. 302), em contrapartida temos Judith Butler (2003) quebrando as barreiras sobre o assunto em seu trabalho originalmente intitulado "Gender Trouble - Feminism and the subversion of Identity", onde questiona a visibilidade da política feminista sem alcançar os objetivos como um sujeito na categoria de mulheres, uma vez que o "nós" do feminismo não passa de uma construção imaginária que jamais representará de forma precisa todos os indivíduos que pretende

5 A expressão 'Ideologia de Gênero' tem um intuito de diminuir as discussões levantadas acerca do estudo de gênero e todas as vertentes que a englobam. O termo é estritamente utilizado por grupos conservadores, sejam pautadas na religião, política e até na educação. 


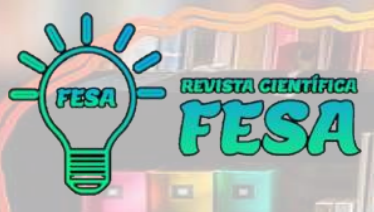

Set. 2021

v. 1, n. 8, 41-62

ISSN: $2676-0428$

representar; porém, aponta para a importância de que a representação se dê, "considerando a condição cultural difusa na qual a vida das mulheres era mal representada ou simplesmente não representada".

Contudo, no aspecto que nos remete sobre o corpo da mulher, a religião, e principalmente a Igreja Católica foi a instituição que mais ditou modos com uso de nossos corpos e ainda hoje compete com outras esferas religiosas agenciadoras do corpo, como por exemplo os protestantes. Para Claudirene Bandini (2004), apesar dos evangélicos (protestantes) evidenciar a alma como a questão superior da salvação, é no corpo, no entanto, que se prova a experiência religiosa. O corpo é para as Igrejas protestantes, a primeira expressão da "mudança individual" provocada pela fé, e isto só é possível porque os evangélicos possuem características referentes ao corpo (a aparência) diferenciadas dos fiéis de outras religiões, produzindo uma gestualidade tipicamente religiosa e comportamentos religiosos que evidenciam a tentativa de moralização do corpo.

Desse modo, a partir das mudanças na configuração da esfera religiosa, na qual a separação entre Igreja e Estado associada a uma ideia de liberdade de crença gera a pluralidade religiosa, e onde a discussão entre fé e razão se intensificam no âmbito da ciência moderna, os discursos sobre o corpo vão, consequentemente, se alterando. Mas, ao contrário de assistirmos à completa libertação, o que pudemos notar foi a multiplicação de discursos sobre o sexo e, consequentemente, sobre o corpo (Foucault, 1985).

Essas mudanças na esfera religiosa influenciaram diretamente as mudanças dos padrões corporais e comportamentais, reforçando as ideias políticas do Estado, no qual o papel da religião se interliga ao se acomodar às novas demandas corporais ao longo do tempo, enquanto a política em seu padrão de dominação da sociedade, exerce poder sobre os corpos, modificando e ressignificando de acordo com suas necessidades de governo.

\section{A FALÁCIA DA IDEOLOGIA DE GÊNERO E A (IN) CULTURALIZAÇÃO DA DEMOCRACIA BRASILEIRA}

A política e autenticidade religiosa no Brasil perpassou por um longo processo e que é resultado da própria história brasileira como sociedade, e acompanha desde o ano de 1500. A Igreja se estabeleceu no poder, no período 
colonial, como um modelo de Catolicismo, e também chamado de Cristandade. Neste período, a Igreja era subordinada ao Estado e a instituição funcionava como instrumento de dominação social, político e cultural. E somente, no chamado segundo reinado, em 1840, a Igreja deixa de ser uma instituição vinculada à Coroa luso-brasileira, e volta sob as ordens direta do Papa. (Azevedo, 2004, p.111-112).

E como tal, acompanhando sempre as mudanças políticas no Brasil, a Igreja se manteve sempre em paralelo com os seus interesses de dominação e desde a primeira Constituição de 1934, registramos a influência da religião católica, impondo o ensino religioso nas escolas públicas, a presença de capelães militares nas Forças Armadas e a subvenção estatal para as atividades assistenciais ligadas à Igreja. Contudo, o Brasil como uma sociedade colonial estruturada através da escravidão, sempre houve em sua consolidação como país, o modelo da subordinação do senhorio em todas as esferas sociais, além do mais, por essa questão houve uma grande miscigenação com as populações indígenas e com os escravos negros vindos da África. Transformando neste contexto, os excluídos da sociedade, a maior parte da população, de homens e mulheres livres marginalizados através do modelo escravocrata, compactuando com Silva e Luiz 2012, onde afirmam que:

\footnotetext{
"A sociedade brasileira carrega per si uma riqueza cultural múltipla, que se tornou híbrida no decorrer da história e guarda consigo determinantes da lógica imposta pelo modelo eurocêntrico de desenvolvimento. Constituída por diferentes grupos e etnias a sociedade brasileira foi se estruturando ao longo dos anos de colonização e expansão econômica e cultural. Podemos dizer que o Brasil é resultado do movimento mundial de expansão geográfica, sendo condicionado pela visão eurocêntrica de desenvolvimento." (p. 05, 2012).
}

E aqui, lançamos a construção do modelo patriarcal, que foi base estrutural da sociedade brasileira, e seguido da ideia conceitual de Weber, "chama-se patriarcalismo a situação na qual, dentro de uma associação, na maioria das vezes fundamentalmente econômica e familiar, a dominação é exercida (normalmente) por uma só pessoa, de acordo com determinadas regras hereditárias fixas". A família brasileira fundamentada no patriarcalismo, tornou a história social da 


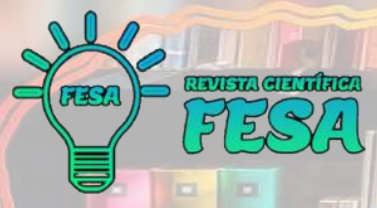

'casa-grande' 6 de praticamente todo brasileira: "da sua vida doméstica, conjugal, sob o patriarcalismo escravocrata e polígamo; da sua vida de menino; do seu cristianismo reduzido à religião de família e influenciado pelas crendices da senzala." (Freyre, 2003, p. 44).

No entanto, foi na Constituição Brasileira de 1988 que se iniciou a ruptura de uma nova concepção de república e democracia, primando pela liberdade, igualdade e respeito às diferenças humanas. Neste novo recomeço, o processo de reconstrução da democracia no Brasil ganhou impulso com o fim da ditadura militar, em 1985. E, de acordo com José Murilo de Carvalho:

Havia ingenuidade no entusiasmo. Havia a crença de que a democratização das instituições traria rapidamente a felicidade nacional. Pensava-se que o fato de termos reconquistado o direito de eleger nossos prefeitos, governadores e presidente da República seria garantia de liberdade, de participação, de segurança, de desenvolvimento, de emprego, de justiça social (Carvalho, 2004, p. 7).

A intenção primária dos brasileiros e brasileiras nesse contexto acima descrito pelo teórico, era de participar, agregar valor de causa na política, serem ouvidos e ouvidas. No entanto, lembramos que o Estado Democrático de Direito, neste primeiro momento estavam constantemente sendo violados através da liberdade e igualdade que são direitos constitucionais. E por isso, para Norberto Bobbio (2004) "sem direitos reconhecidos e protegidos, não há democracia; sem democracia, não existem as condições mínimas para a solução pacífica dos conflitos". Ou seja, o Estado Democrático de Direito brasileiro, só será consolidado quando os direitos fundamentais forem efetivamente reconhecidos e protegidos no plano tanto político quanto jurídico.

Desse modo, o estado democrático deve garantir uma convivência harmoniosa entre pessoas de distintas crenças, porém com o atual momento que vivemos no Brasil, os direitos sexuais e reprodutivos são alvos cada vez mais nas políticas públicas e adotada pelas instituições religiosas, que consideram a reprodução como um dom divino, e a sexualidade um mero meio para o alcance dessa finalidade divina da reprodução. Associada a essa grande guerra, nasce

6 Seguindo a mesma ideia do autor Gilberto Freire, a Casa-grande é representada pelo sistema patriarcal de colonização portuguesa do Brasil, que o colonizador começou, ainda no século XVI, a levantar no Brasil [...] uma expressão nova, correspondendo ao nosso ambiente físico e a uma fase surpreendente, inesperada, do imperialismo português: sua atividade agrária e sedentária nos trópicos; seu patriarcalismo rural e escravocrata. (Gilberto Freyre, 2006). 


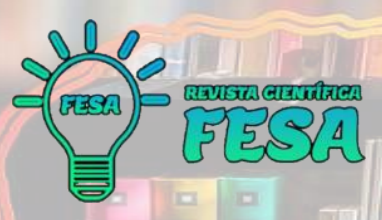

Set. 2021

v. 1, n. $8,41-62$

ISSN: 2676-0428

o fundamentalismo religioso, que iniciou através do protestantismo conservador do Sul dos Estados Unidos, início do século XX.

O fundamentalismo religioso se baseia principalmente contra a modernidade das interpretações literárias dos textos bíblicos contrapondo os avanços da biologia, através da teoria darwinista que afirma a ocorrência da evolução das espécies, ou seja, os conservadores religiosos não aceitam a hermenêutica bíblica. No entanto, muitas mulheres, teólogas feministas têm se aprofundado em hermenêutica bíblica e levantado discussões acerca do modo que a interpretação dos líderes religiosos, em sua maioria homens, fazem em diminuir o papel das mulheres e tal como o direito em decidir sobre seu corpo.

Atualmente no Brasil, muitas atuações ferem a laicidade ${ }^{7}$, firmada pela constituição, principalmente quando diz respeito ao corpo da mulher. $\mathrm{O}$ aborto, por exemplo, é considerado crime do ponto de vista da lei e pecado aos olhos da Religião. Por isso, a imagem da mulher transmitida pela mídia limita o papel desta a maternidade como destino exclusivo, em contrapartida transforma o assunto aborto como forma quase diabólica e eleva a imposição patriarcal do Estado sobre os direitos sexuais reprodutivos. Consequentemente para aprofundar ainda mais a discussão, é notório a inexistência de uma representatividade política nos muitos projetos parlamentares discutidos nas assembleias em todo país.

Os projetos parlamentares de inclinação pró-vida, que inclui antiaborto e defesa dos direitos dos recém-nascido, em sua maioria quando finalizaram para identificar a penalização em leis, foram principalmente inclinados por autores políticos católicos, espírita e evangélicos. E a pergunta mantém: Vivemos de fato em um país laico? A diferenciação de laicidade depende do gênero? Por que em um país dito como laico as mulheres ainda têm que lutar por um direito já existente? Infelizmente, no tocante da necessidade de uma resposta, a reflexão torna-se a fortaleza de uma necessidade constante de buscar. Uma busca incansável, através dos textos, autoras e histórias de mulheres que desejam de fato, manter uma vida por igual, equi igual dos homens.

A pouco, em agosto de 2020, século XXI, tivemos um episódio verídico e

7 A Laicidade é a forma institucional que toma nas sociedades democráticas a relação política entre o cidadão e o Estado, com intuito de garantir simultaneamente a liberdade de todos e a liberdade de cada um. Ou seja, separa o domínio público, onde se exerce a cidadania, e o domínio privado, onde se exercem as liberdades individuais (de pensamento, de consciência, de convicção) e onde coexistem as diferenças (biológicas, sociais, culturais). 

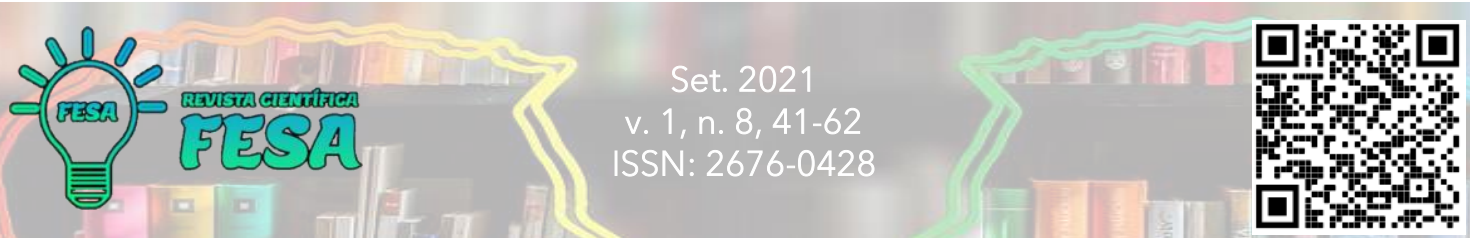

que chocou internacionalmente a todos, e ressaltamos que este não é um caso isolado, e já antes apresentado em vários pontos do Brasil casos como esse, onde uma menina de 10 anos, após meses a ser estuprada pelo tio, engravidou. E mesmo amparada pela Legislação, onde prever a interrupção da gravidez em caso de violências sexual, a criança teve o aborto negado em primeira instância e só depois foi autorizado pelo Estado Espírito Santo, no entanto o procedimento foi realizado em Pernambuco.

O arcebispo Dom Fernando Saburido, de Olinda e Pernambuco, por meio de um vídeo publicado na rede social Twitter, se pronunciou: "Como arcebispo, quero contestar inteiramente essa decisão, a igreja defende a vida em qualquer circunstância." Grupos fundamentalistas de extrema-direita, também reivindicaram a frente do hospital, onde a criança iria realizar o procedimento, e chamaram o médico e a família da criança, com gritos de "assassinos".

É neste contexto que se vislumbra a violência biopolítica exercida sobre o corpo como território, especialmente o corpo feminino, e perpetuada no limbo entre regra e exceção, e suas várias faces e estratégias de manifestação. Uma delas, realizada sob o manto da legalidade estatal é aquela perpetuada diante do sinuoso e cruel controle dos aspectos reprodutivos [...] Lembramos que a prática do aborto, independentemente de sua legitimidade e legalidade, passou a ser criminalizada no Ocidente a partir de meados do século XIX, e a partir do século XX começa a ser definitivamente revogada nestes mesmos países. (Delajustine; Rodrigues, 2019, p.59).

Todo esse fundamentalismo religioso, tem como consequência a configuração de uma cidadania religiosa. Na maioria dos países da América Latina, o impacto histórico e cultural da Igreja Católica produziu modelos de pertencimento nacional demarcados por princípios católicos, dado à colonização. (Vaggione, 2017, p.3). E mesmo o Estado, declaradamente laico ${ }^{8}$, é objeto de pressões de todo o tipo, não apenas pela presença direta das hierarquias religiosas, mas também por associações comunitárias de caridade que incluem uma agenda retrógrada dentro da agenda política.

De acordo com o o artigo 5ำ, da Constituição Federal, estabelece que "todos são iguais perante a lei, sem distinção de qualquer natureza, garantindo-se aos brasileiros e aos estrangeiros residentes no País a inviolabilidade do direito à vida, à liberdade, à

8 Um Estado é considerado laico quando promove oficialmente a separação entre Estado e religião; devem tratar todos os seus cidadãos igualmente, independentemente de sua escolha religiosa, e não deve dar preferência a indivíduos de certa religião. Garantindo neste caso, e protegendo a liberdade religiosa de cada cidadão, evitando que grupos religiosos exerçam interferência em questões políticas.

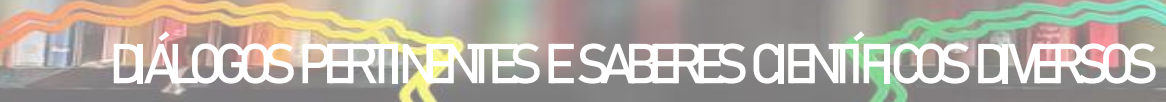




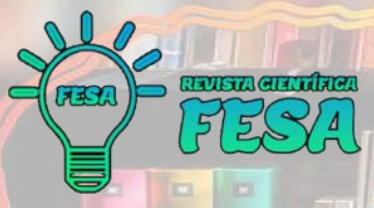

igualdade, à segurança e à propriedade, nos termos seguintes [...]". Joan Scott em 2005, no seu artigo super esclarecedor sobre "Enigma da Igualdade", afirmou que: "os indivíduos devem ser avaliados por eles mesmos, não por características atribuídas a eles como membros de um grupo." Ou seja, a igualdade só pode acontecer de fato quando os indivíduos são considerados unicamente como indivíduos.

A igualdade historicamente é um princípio absoluto e não é a inexistência da diferença, mas sim saber reconhecer a diferença e corroborando com Palmer quando afirmou no Dictionary of the of Ideas: "A igualdade requer um ato de escolha, pelo qual algumas diferenças são minimizadas ou ignoradas enquanto que outras são maximizadas e postas a se desenvolver". (1973-74, p. 139). O ato de escolher a igualdade, não pode estar vinculada ao gênero, raça, profissão ou mesmo status social e essa afirmação é tão óbvia que nos leva a questionar o porquê que estamos refletindo essa conjectura da mulher ser respeitada tanto em termos legais e morais em pleno século XXI. Então, a questão é simples: Vivemos constantemente mantendo os padrões de ensino e de perspectiva para o homem e para a mulher, o que torna um grande tabu apresentar a verdade onde a sociedade manteve-se ano após ano um vício patriarcal e linear de conduta e convívio social. De acordo com Michel Foucault (1988) em seu livro "História da Sexualidade - Vontade de Saber", a dominação patriarcal nasceu no ato da confissão, onde a Igreja Católica detinha a verdade absoluta de como deveria ser ou fazer a mulher e o homem dentro e fora do seu convívio familiar.

Reforçando que a Religião tende sempre a manifestar sua intensa pseudo verdade com relação a vida da mulher, e este processo lentamente foi repassado desde os primórdios da construção da sociedade, e quando temos em papel através da Constituição Brasileira, um direito que compete a todo ser humano que vive em democracia e em um país laico, não se fazer valer, só nos faz pensar de fato, o corpo que me mantém e que faz parte de mim como mulher, ser humano, brasileira, é meu de fato? Ou o corpo nunca me pertenceu?

\section{CONSIDERAÇÕES FINAIS}

A verdade é que o Estado brasileiro não é efetivamente laico, apesar de está descrito em nossa constituição, ainda há um longo caminho para que ocorra 


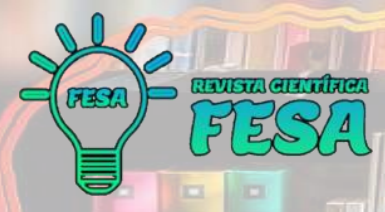

Set. 2021

v. 1, n. 8, 41-62

ISSN: $2676-0428$

a desconstrução do caráter patriarcal enraizada na política que rege o país e na religião que aliena toda a sociedade transformando as mulheres, que também são cidadãs, como sujeitos que não possuem plenos direitos.

O corpo da mulher, mantém desde os primeiros tempos subordinado a outrem, e a quebra da roda que gira década por década, século por século custa de fato a ocorrer de forma branda. A ruptura de tão mudança de atitude social, requer uma conscientização de dentro para fora. Dentro de cada um, na família, e ao fim transpassando para as políticas públicas, e tornando a cultura de forma mais igual.

No entanto, a igualdade não será vencida sem luta, que será inevitavelmente necessária e cabe não só a mulher, e sim a todos os cidadãos brasileiros mudar a forte influência das posições hegemônicas das instituições religiosas apoiada pelo Estado e presente nos processos de sociabilidade no cotidiano da sociedade. Devemos lutar pela implementação de valores maiores e que possam combater o desequilíbrio que se está vivendo, através da democracia, justiça social e principalmente da igualdade. Somente com a busca da pluralidade e liberdade individual e coletiva poderemos evoluir para uma consciência interna de humanidade.

Lembremos que fortalecer os movimentos feministas no Brasil, trará uma construção de espaços para mulheres nos setores diversos dentro da sociedade, levando a oportunidade da representatividade, e junto a isso, a reflexão de desconstruir a lógica patriarcal dominante no país, que controla os nossos corpos.

Todos os movimentos de resistência na história de transgressão do feminismo tiveram como principal protagonista o corpo feminino. Ou seja, mudam os tempos, mas permanece a reivindicação do corpo como seu e reforçando Michele Perrot "toda mulher em liberdade é um perigo, e ao mesmo tempo, está em perigo, um legitimando o outro. Se algo de mau lhe acontece, ela está recebendo apenas aquilo que merece, porque o corpo das mulheres não lhe pertence" (Perrot, 2005, p. 447). A afirmação da teórica reforça que o debate crítico do direito do corpo da mulher precisa estar vivo, o direito civil precisa valer e então teremos a chance de tornar o meu corpo, o seu corpo, e o corpo de todas as mulheres que sejam ou se sintam violadas, autonomia única da própria. 


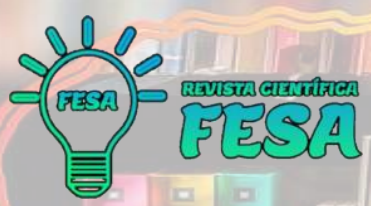

Set. 2021

v. 1, n. 8, 41-62

ISSN: $2676-0428$

\section{REFERÊNCIAS BIBLIOGRÁFICAS}

ALVES, B. M., \& Pitanguy, J. O que é feminismo? (Coleção Primeiros Passos). São Paulo: Brasiliense. 1991.

ARAÚJO, Emannuel. A Arte da Sedução: sexualidade feminina na colônia. In: PRIORE, Mary Del (Org.). História das Mulheres no Brasil. 9. ed. São Paulo: Contexto, p. 45- 77, 2010.

AZEVEDO, Dermi. A Igreja Católica e seu papel político no Brasil. Estudos Avançados, 18 (52), p. 111, 2004.

BAUER, Carlos. Breve história da mulher no mundo ocidental. São Paulo: Xamã. Edições Pulsar. 2001.

BANDEIRA, Marina. A Igreja Católica na virada da questão social: anotações para uma história da Igreja no Brasil. Rio de Janeiro: Vozes. 2000.

BANDINI, C. Corpo, religião e identidade social: marcas simbólicas da experiência pentecostal notas de uma pesquisa. Mandrágora, São Bernardo do Campo, v. 9, n. 10, p. 40-48, 2004.

BEAUVOIR, Simone de. O segundo sexo: fatos e mitos. São Paulo: Difusão Européia do Livro. 1970.

BÍBLIA SHEDD: Traduzida em português por João Ferreira de Almeida. 2 ed. rev. atual. São Paulo: Vida Nova. 1998.

BOBBIO, Norberto. A era dos direitos. Trad. Carlos Nelson Coutinho. Rio de Janeiro: Elsevier. 2004.

BOURDIEU, Pierre. Trabalhos e projetos. In: R. Ortiz (dir). A sociologia de Pierre Bourdieu. São Paulo: Olho D’Água, p.20, 2003.

BRASIL. Assembleia Nacional Constituinte. Diário da Assembleia Nacional Constituinte (Diário da ANC). Brasília, Diversos números. 1987/88.

BUTLER, Judith. Corpos que pesam: sobre os limites discursivos do "sexo". In: Louro, Guacira Lopes. O corpo educado: pedagogias da sexualidade. Belo Horizonte: Autêntica, p. 153-172, 1999.

BUTLER, Judith. Problemas de gênero: feminismo e subversão da identidade. Tradução de Renato Aguiar. Rio de janeiro: Civilização Brasileira. 2003

CHAUÍ, M. Convite à filosofia. São Paulo, São Paulo: Ática. 1997.

CPF (Conselho Pontifício para a Família). Família, matrimônio e "uniões de fato". Vaticano. Disponível em: <www. vatican.va>. Acesso em: 12 set. 2020. 2000. 

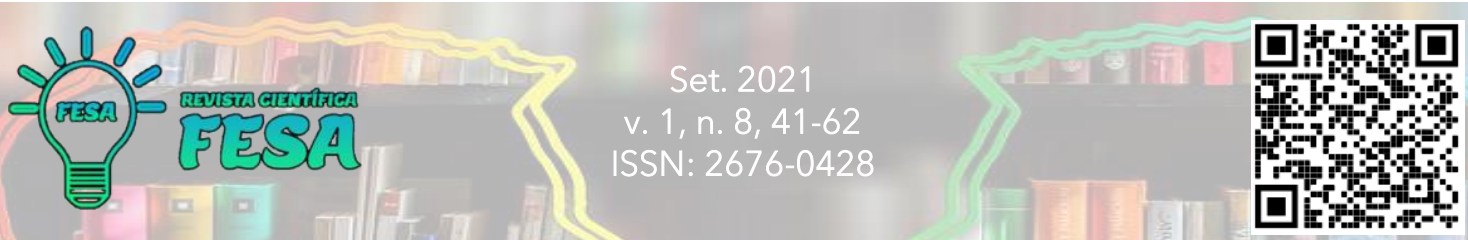

CONFERÊNCIA EPISCOPAL PERUANA. A ideologia do gênero: seus perigos e alcances. Lima,Peru. 2008 Disponível em: <http://img.cancaonova.com/noticias/pdf/281960_IdeologiaDeGenero_PerigosEA Icances_ConferenciaEpiscopalPeruana.pdf $>$. Acesso em: 12 set. 2020.

COLLING, Ana Maria. 50 anos da ditadura no Brasil: questões feministas e de gênero. OPSIS, Catalão. v.15, n.2, p. 375, 2015.

COLLING, Ana Maria; ACOM, Ana Carolina. Corpo feminino, corpo político: de fustigado a devorador do instituído. Revista Prâksis. Novo Hamburgo, a.16, n.2, mai./ago. 2019.

CORRIGAN, Philip."Making the boy: meditations on what grammar school did with, to and for my body". In Henri Giroux (org.), Postmodernism, feminism and cultural politics. Nova York: State University of New York Press, p.196-216, 1991.

COSTA, Jurandir Freire. F. Norma médica e ordem familiar. 4. ed. Rio de Janeiro: Graal. 1999.

DELAJUSTINE, Ana Claudia; RODRIGUES, Ana Kravczuk. O corpo da mulher sob tutela do fundamentalismo religioso: o controle reprodutivo feminino. Anais do VI Congresso Latino-Americano de Gênero e Religião, São Leopoldo, v.6, p.55-65, 2019.

FOUCAULT, Michel. Microfísica do Poder. Rio de Janeiro: Graal. 1979.

FOUCAULT, Michel. História da sexualidade: o cuidado de si. 10 ed. Rio de Janeiro. 1985.

FOUCAULT, Michel. Vigiar e punir: nascimento da prisão. 20ª ed. Petrópolis: Vozes. 1987.

FOUCAULT, Michel. História da Sexualidade I: a vontade do saber. 7. ed. Rio de Janeiro: Edições Graal. 1988.

FONSECA, Maria Elizabeth Melo. Religião, mulher, sexo e sexualidade: Que discurso é esse? Paralellus. Recife, n. 4, p.216, 2001.

FISCHER, R. M. B. Mídia e educação da mulher: Uma discussão teórica sobre modos de enunciar o feminino na TV. Revista Estudos Feministas, 9 (2), 586599, 2001.

FREYRE, Gilberto. Casa-grande e senzala: formação da família brasileira sob o regime da economia patriarcal; apresentação de Fernando Henrique Cardoso - 51를 edição. São Paulo: Global. 2006. 
GOELLNER, Silvana Vilodre; FIGUEIRA, Márcia Luiza Machado. Corpo e gênero: a revista Capricho e a produção de corpos femininos. Motrivivência, Florianópolis, vol. 2, n. 19, p. 1-13, jul./dez. 2002.

HABERMAS, J. Entre naturalismo e religião: estudos filosóficos. Rio de Janeiro: Tempo Brasileiro. 2007.

KOFES, Suely. Categorias analítica e empírica: Gênero e mulher: Disjunções, conjunções e mediações. In: Mesa-redonda: "Estudos de Gênero: a interdisciplinaridade no campo teórico e a subjetividade no campo metodológico". Belo Horizonte: XVIII Reunião da Associação Brasileira de Antropologia (ABA), p. 19-30, 1992.

LE BRETON, David. A sociologia do corpo. $2^{\text {a }}$ ed. Tradução Sônia M.S. Fuhrmann. Petrópolis: Vozes. 2009.

LOURO, Guacira Lopes. Teoria Queer - Uma política pós-identitária para a educação. Revista Estudos Feministas, n.2, p.541-553, 2001.

LOURO, Guacira Lopes. Gênero, sexualidade e educação: uma perspectiva pós-estruturalista. 6. ed. Petrópolis: Vozes. 2003.

LUCAS, Luciane; HOFF, Tânia. Formas sutis de dominação hierarquizada: corpo e feminização da pobreza. Ex aquo, n.17, p. 133-154, 2008.

MASS, M. Les techniques du corps. Sociologie et anthropologie. Paris: PUF, p. 404-405, 1950.

PALMER, R. R. "Equality." Wiener, Philip P. (ed.). Dictionary of the History of Ideas. New York: Scribner. 1973-74.

PERROT, Michelle. As mulheres e os silêncios da História. Bauru,SP: EDUSC. 2005

PORTER, Roy. História do Corpo. In: Burke, Peter. (Org). A Escrita da História: Novas Perspectivas. São Paulo: Unesp, p. 325, 1992.

RAGO, Margareth. Ser mulher no século XXI ou Carta de alforria. In: Venturi, Gustavo; Recamán, Marisol; Oliveira, Suely de. (Org). A mulher brasileira nos espaços público e privado. São Paulo: Editora Fundação Perseu Abramo, p. 31-32, 2004.

RIBEIRO, Arilda Ines Miranda. Mulheres Educadas na Colônia. In: Lopes, Eliane Marta Teixeira; Filho, Luciano Mendes de Faria; Veiga, Cynthia Greive (Orgs.). 500 Anos de Educação no Brasil. 2. ed. Belo Horizonte, MG: Autêntica, p. 79-94, 2000.

SANTOS, Lionês Araújo dos. O corpo na cultura e a cultura da "reforma" do corpo. RBSE - Revista Brasileira de Sociologia da Emoção, v. 10, n.30: 406- 
414, 2011.

SOARES, Carmen Lucia; Fraga, Alex Branco. Pedagogias dos corpos retos: das morfologias disformes às carnes humanas alinhadas. Pro-Posições. Campinas, v. 14, n.2, p.77-90, 2003.

SCOTT, Joan. O Enigma da Igualdade. Estudos Feministas, Florianópolis, p. 11-30, 2005.

SILVA, S. C.; LUIZ, D. E. C. Cultura política, participação e democracia no Brasil: reflexões a partir da perspectiva gramsciana. In: SEMINÁRIO NACIONAL ESTADO E PODER:SOCIEDADE CIVIL, Uberlândia, p.1-12, 2012.

VAGGIONE, Juan Marco. La Iglesia Católica frente a la política sexual: la configuración deuna ciudadanía religiosa. Cadernos Pagu. Dossiê Conservadorismo, Direitos, Moralidades e Violência. n. 50, p. 28, 2017. 